\title{
Death-penalty analysis reveals extent of wrongful convictions
}

\section{Statistical study estimates that some $4 \%$ of US death-row prisoners are innocent.}

\section{Sara Reardon}

28 April 2014

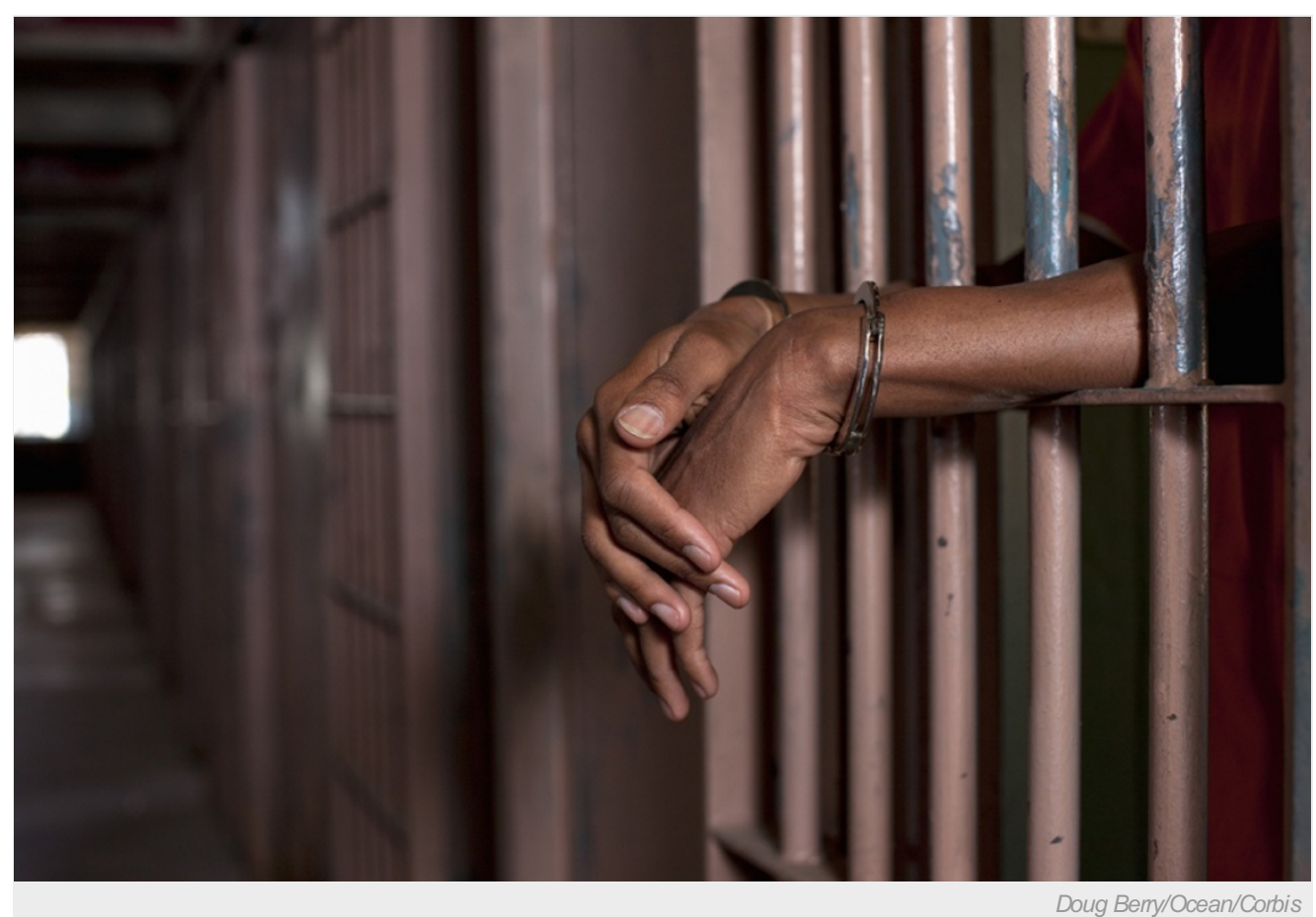

The chances of exoneration increase the longer a person remains on death row, according to a study.

At least one in 25 people on death row in the United States would be exonerated if given enough time, researchers have found. The study, which used statistical methods to extrapolate from available data, is one of the first to try to quantify the rate of false convictions.

The work attempts to shed light on a notoriously difficult task: gauging the number of people falsely convicted of crimes. Few convictions result in an exoneration, most of those convicted never manage to prove their innocence and many cases do not have their final outcomes recorded, so data are not available to researchers. Innocent people also frequently plead guilty in the hope of reducing their sentence, effectively eliminating themselves from any analysis. Therefore, quantifying exonerations is the only way to get a glimpse of the extent of wrongful convictions, says lead author Samuel Gross, a criminologist at the University of Michigan Law School in Ann Arbor.

Gross and his colleagues analysed the rate of exonerations among prisoners on death row, whose outcomes are carefully tracked by the US Bureau of Justice Statistics in Washington DC. In a previous report, the researchers found that less than $0.1 \%$ of prison sentences are death sentences, yet capital cases accounted for $12 \%$ of exonerations between 1989 and 2012. Gross attributes the disparity to the tendency of lawyers and courts to work harder to definitively determine guilt when a person's life is on the line.

\section{A case for delay}

But many death sentences are never carried out. Courts often change a convict's sentence to life imprisonment, or the accused dies from suicide or natural causes while on death row. To determine what would have happened to these prisoners had they remained there, Gross's team relied on a statistical method known as a survival curve, which is commonly used in epidemiology to measure the number of people in a population who die from a specific cause over a certain period, and so extrapolate the rate of deaths for longer periods of time.

The longer a person stayed on death row, the team found, the higher the chance that he or she would be exonerated. Furthermore, the researchers calculated that if all of those sentenced to death were kept on death row indefinitely without being executed, receiving a life sentence or dying of another cause, at least $4.1 \%$ would eventually be exonerated. That number still underestimates the rate of 
false convictions, Gross says, because many innocent people never manage to prove their innocence.

Because a longer death row stint means a greater chance of exoneration, people who are put to death quickly after their convictions could be more likely to have been innocent than the population of convicts as a whole - likely because there has not been as much time for subtler pieces of evidence to come to light.

According to James Liebman, a lawyer at Columbia Law School in New York City who was not involved in the study, the statistics suggest something of a paradox. Often a convict is lucky enough to have his death sentence commuted to life in prison, by a state governor for example, because of lingering doubt about his guilt. But because fewer people with life sentences are exonerated, Liebman says, "that luck will be bad luck because there's a lesser change of having that error discovered."

Nature I doi:10.1038/nature.2014.15114

\section{References}

1. Gross, S. R., O'Brien, B., Hu, C. \& Kennedy, E. H. Proc. Natl Acad. Sci. USA http://dx.doi.org/10.1073/pnas.1306417111 (2014). 